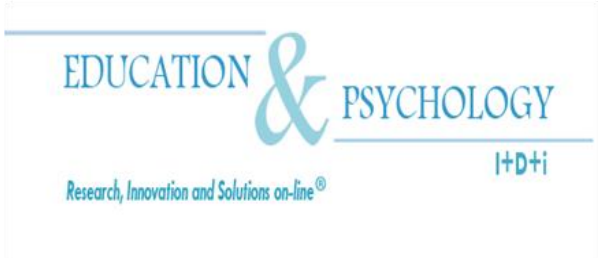

\title{
Exploring Suitable Emotion-Focused Strategies in Helping Students to Regulate Their Emotional State in a Tutoring System: Malaysian Case Study
}

\section{Mohd Zaliman Mohd Yusoff ${ }^{1}$, Nor Azan Mat Zin ${ }^{2}$}

\footnotetext{
${ }^{1}$ Software Engineering Department, College of Information Technology, University Tenaga Nasional, Kajang, Selangor

${ }^{2}$ Faculty of Information Science and Technology, Universiti Kebangsaan Malaysia (UKM), Kajang, Selangor
}

\begin{abstract}
Malaysia
Correspondence: Mohd Zaliman Mohd Yusoff, Software Engineering Department, College of Information Technology, University Tenaga Nasional, Malaysia .E-mail: Zaliman@uniten.edu.my
\end{abstract}

(C) Education \& Psychology I+D+i and Editorial EOS 


\begin{abstract}
Introduction. This study explored the suitable emotion-focused strategies in helping students to regulate their emotional state in a self-regulated tutoring system.

Method. A questionnaire which consists of 25 different regulation strategies adapted from Ways of Coping questionnaire (WCQ) was used to determine the strategies deployed by the students to regulate their emotional state during stressful learning episodes. The questionnaire was distributed in person to 227 unpaid students (132 males and 95 females) from the College of Information Technology, Universiti Tenaga Nasional in Malaysia. This questionnaire was distributed at the beginning of their class and no time limit was imposed. Students were asked to hand in the survey as soon as they had completed the questionnaire.
\end{abstract}

Results. Findings from this study indicated that students used both emotion-focused and problem-focused strategies as their self-regulation strategies in dealing with stressful learning episodes. In addition, the selection of the self-regulation strategies was influenced by students' gender and religion.

Discussion and Conclusion. Moreover, two emotion-focused strategies were identified to potentially be integrated into a self-regulated tutoring system framework: relaxation exercise and supplication strategies.

Keywords: Emotion-focused strategy, Student emotion regulation, Self-regulated tutoring system, Emotion and Learning 


\title{
Exploración de adecuadas estrategias centradas en la emo- ción para ayudar a los alumnos a regular su estado emo- cional en un sistema autorregulado de tutorización. Un estudio de caso de Malasia.
}

\begin{abstract}
Resumen
Introducción. Este estudio exploró las estrategias centradas en las emociones apropiadas para ayudar a los alumnos para regular su estado emocional en un sistema de tutoría autorregulado.

Método. Un cuestionario que consta de 25 diferentes estrategias de regulación adaptados de maneras de hacer frente cuestionario se utilizó ( Eliminatorias ) para determinar las estrategias desplegadas por los alumnos para regular su estado de ánimo durante los episodios de aprendizaje de estrés. El cuestionario se distribuyó en persona a 227 estudiantes no remunerados (32 varones y 95 mujeres) de la Facultad de Tecnología de la Información, Universiti Tenaga Nasional en Malasia. Este cuestionario fue distribuido a principios de su clase y sin límite de tiempo se impuso. Los estudiantes se les pidió que entregaran la encuesta, tan pronto como habían respondido al cuestionario.
\end{abstract}

Resultados. Los resultados de este estudio indicaron que los estudiantes utilizan ambas estrategias centradas en las emociones y el problema, enfocada como sus estrategias de autorregulación en el tratamiento de episodios de aprendizaje de estrés. Además, la selección de las estrategias de autorregulación fue influenciado por el género y la religión estudiantes .

Discusión y Conclusión. Por otra parte, se identificaron dos estrategias centradas en las emociones que potencialmente pueden integrarse en un marco de sistemas de tutoría autorregulado: ejercicio de relajación y estrategias de ayuda.

Palabras clave: estrategia centrado en la emoción, la regulación emocional del estudiante, el sistema de tutorías autorregulado, Emoción y Aprendizaje. 


\section{Introduction}

For a long time, educational theorists largely failed to acknowledge the important role of emotion in academic achievement and learning. Until recently, our knowledge about students' emotions in educational environments remained rather limited even though traditional theories of achievement and motivation posited emotions such as pride and shame as central components (Pekrun, 2011). According to Bandura (2010), the relationship between emotion and learning achievement was rarely analyzed empirically. One possible reason for the lack of research in learning involves ethical consideration, such as the direct assessment of students' emotions during their learning process might negatively influence their learning outcomes and interrupt their problem solving efforts (Goetz et al., 2008).

Much research in educational settings has been concerned predominantly with the rational and scientific approaches to intellectual enquiry (Pekrun, 2011). Bandura (2010) shares a similar view. For him, most efforts are geared towards understanding the cognitive dimension in the search for improvement of quality in teaching and learning. Similarly, Goetz et al. (2008) reports that more focus are given to the cognitive domain in instructional and assessment strategies. However affect, particularly emotions, has been acknowledged recently as an important factor in shaping the change in cognitive functions (Pekrun, 2011).

So, if cognition is indeed intertwined with affect, then there may be some value in studying the role of emotion in educational settings. Emotions mediated by appropriate attention, self-regulation and motivation strategies can lead to a positive effect on learning and achievement (Pekrun and Stephens, 2012). For example, positive emotion promotes a more inclusive form of thinking that permits a person to be more creative and willing to take risks that could guide him to produce better learning outcomes.

Likewise, negative emotion such as fear and anxiety can assist students in learning. These elicited emotional states may alert students to become more careful and analytic in their learning so that a better learning outcome can be produced which, in turn, improves their negative affective states. However, excessive negative emotions may reduce student's problemsolving ability in learning (Bandura, 2011). 
A growing concern for the vital role of affect in education is evident from the work of academics over the last 10 years (Schutz, 2007). The growing awareness and interest in emotions and students' achievement is reflected in several special issues on emotion in learning (Van der Meij, 2008 ). However, as suggested by some literature (Yeh, 2005), student's emotions are influenced by their religion and culture (i.e. especially in Malaysian context). Thus, it is important to conduct comparison study of the emotion-focused implementation strategies based on student's religion and cultural background.

Taken together, a careful study on emotions in a learning environment is an interesting are to explore. Thus, we organize this paper as follows: discussion on effect positive and negative emotions on learning is presented in next two sections and followed by discussion on emotion regulation process and its strategies. Subsequently, a section on material and procedure used for the experiment is presented. Next, results and discussion of the study are presented and followed by a section on the limitation of the study. Finally, we conclude this paper with a conclusion section.

\section{The effect of positive emotions on learning}

The ability to momentarily broaden the scope of cognition is the first advantage of a positive emotional state. It allows an individual to become more creative, flexible, and efficient (see Fredrickson (2005), for a review). Fredrickson (2005) argues that these characteristics allow an individual to build an array of enduring personal resources and, in consequence, initiate an upward spiral towards an increase in the state of well-being. Likewise, evidence from the study conducted by Isen and colleagues shows that people experiencing positive emotions display patterns of thought that are notably unusual, flexible and efficient (Isen $\&$ Reeve, 2005 as cited in Tugade \& Fredrickson, 2004).

In an experiment, Fredrickson (2005) conducted a study to examine the relationship between positive emotions and thought-action repertoire. In their study, participants were experimentally induced to either positive (i.e. joy and contentment), negative (fear and anger) or neutral emotions after which they listed all thoughts about what they would like to do right then (a measure of breadth in participants' thought-action repertoire). They found that indi- 
viduals in a positive emotional state listed significantly more things than those in the negative or neutral emotional state.

Broadening students' scope for action is the second advantage of students being in a positive emotional state. Renninger (1992) studied children's reactions when playing with objects that elicited interest. He found that children in a positive emotional state showed a wider range of types of play, more variations of action within play types and longer play episodes when dealing with elicited interest objects.

Finally, positive emotions have the ability to correct, restore, and undo the aftereffects of negative emotions (Lazarus, 1999). It is hypothesised that positive emotions restore autonomic quiescence following a negative emotional arousal. In one experiment, Fredrickson \& Levenson (1998) measured the time elapsed from the start of a randomly assigned film until the cardiovascular reactions induced by the negative emotion returned to baseline levels. They used four cardiovascular reaction measurements; 1) the interval of heart beat period, 2) the pulse transmission time to the ears, 3) the pulse transmission time to the finger and 4) the amount of blood in the tip of the finger (see Fredrickson \& Levenson (1998) for details of the study). They reported that participants in a positive emotional state exhibited faster recovery. This finding indicates that positive emotions have the ability to reduce a negative emotional arousal.

Likewise, Pekrun et al. (2012) suggest that positive emotions are worthy of investigation. They postulate:

“.. emotions help to envision goals and challenges, open the mind to thoughts and problem-solving, protect health by fostering resiliency, create attachment to significant others, lay the groundwork for individual self-regulation, and guide the behaviour of groups, social system, and nations " ( $p$ 149)

There is also evidence to show that positive emotions play a pivotal role in educational settings (e.g. Goetz et al., 2008). For example, Pekrun et al. (2012) highlighted the relevance of positive academic emotions with regard to self-regulation, strategy use, motivation and activation of cognition resources in students. Nevertheless, there is also research on dysfunctional of positive emotions (e.g. Tiba \& Szentagoi, 2005; David et al., 2004). For example, Tiba \& Szentagoi (2005) argue that uncontrolled strong positive emotions such as pride, joy 
and contentment can influence individual behaviour to deploy unrealistic expectation, cognitive bias leading to inappropriate action and strategies, reduce creativity in decision-making , and appraisal components (Lazarus, 1991). In high level sport such as the Olympic Games, positive emotions are perceived as dysfunctional. Positive emotion states such as calm, relaxed, satisfied or too confident can be detrimental to the athlete's performance (Hanin, 2000).

In a learning context, positive emotions may also sometimes require regulation. For example, getting the correct answer to a difficult question could elicit positive emotions such as joy and pride, but lead to inappropriate learning activities if too much attention is given to the elicited emotions. Without regulation, excessive positive emotions can direct the student to focus on the euphoria and underestimate the effort needed to attain a good result. Consequently, they become overconfident and less likely to increase their effort in learning.

Taken together, the findings suggest that a careful approach on positive emotion regulation should be considered in an affective tutorial system framework so that the positive emotion can be nurtured to optimize learning.

\section{The effect of negative emotions on learning}

Negative emotions have been found to be associated with several cognitive and learning deficits. The first is a perceptual deficit. Students in a negative emotional state sometimes cannot recognize the exact emotions they are experiencing (Pekrun, 2011). This may lead to a student sometimes ignoring or denying his emotional state or mislabelling it as physiological. As a result, the student may fail to engage in adaptive strategies for regulating his negative emotions, thereby prolonging his distress.

The second deficit experienced by students in a negative emotional state is that they are inclined to misinterpret the causes of problems associated with their learning or may misinterpret who is responsible for altering their affect (Bandura, 2011). As a result, this deficit may lead the students to seek inappropriate solutions to their problem or not to seek any solution at all, particularly if they believe that the cause of their problem is stable and unchangea- 
ble. They are more likely to wait for others to make them feel happy, rather than to initiate behaviour that will alter their negative feeling.

Knowledge deficit is the third potential disadvantage experienced by students in a negative emotional state. A student in this emotional state may have adequate knowledge but be unable to use it while in a negative emotional state. This knowledge deficit may be a result of never having learned effective strategies for managing negative affect. It is believed that students in a negative emotional state do not engage in effective solutions because they do not expect that the strategies will help modify their negative affect; they expect that engaging in such strategies will produce additional undesirable effects (They also believe that while experiencing negative affect, their skills are not adequate to implement regulation efficiently.

Finally, a student in a negative emotional state may experience enactment deficit. This is about the inability of the student to execute or exercise the necessary responses of his selected solutions of a problem. It is possible that even if students are aware of appropriate strategies, they will be less capable of implementing them because of a general skills deficit or a temporary deficit resulting from their negative affect (Pekrun, 2011). Students with negative affect have been found to generate significantly more irrelevant strategies than students with positive affect, although they did not differ with regard to the total number of alternative strategies generated.

In contrast, there are times when the effects of negative emotions are useful (Margolis \& McCabe, 2006; Kay \& Loverock, 2008). Anxiety enables one to be vigilant for threat; shame can lead one to monitor others' options and to re-establish one's reputation (Barret et al., 2002). There is evidence to show that negative emotions enhance individual performance. For instance, Hanin (2002) reports that negative emotions such as fear, anxiety and tension enhanced athletes' performance. Likewise, musicians and actors need a certain level of anxiety arousal in order to perform well (Eysenck, 1998; Isen et al., 2005).

In the learning context, negative emotions such as test anxiety and mild stress or fear can foster students to be more careful and analytical to avoid making unnecessary errors (Isen et al., 2005). Furthermore, negative emotions provide a helpful warning that alert students to potential bad consequences so that preventive measures can be invoked and coordinated. Similarly, the affective dissonance associated with short term failure can be used as a catalyst to improve students' subsequent performance (Nietfeld et al., 2005). When allowed to explore 
and discuss the causes of their failure, students become more alert and determined to use the learning resources efficiently and devise better strategies in their future learning (Isen et al., 2005).

However, an excessive level of negative emotions (i.e. anxiety and fear) can inhibit students' performance. Repeated errors will create the expectation of mistakes that leads to increased of anxiety, leading to more mistakes until the student's performance collapses. Moreover, there is evidence that extreme levels of negative emotion may also affect selfperception capabilities such as self-confidence (Goetz et al., 2008) and self-esteem (Gross and Barrett, 2011) which increases the level of anxiety and other negative emotions (Isen et al., 2005). This suggests that the regulation of the negative emotions within learning environment is an important matter to explore.

\section{Emotion Regulation Process}

According to Fridja (Fridja 1986), people not only just "have" emotions, but they also regulate them to suit their goals. Emotion regulation, defined broadly, is the process of modulating and managing individual emotional state (Gross, Sheppes, \& Urry, 2011). According to (Gross \& Barrett, 2011), the modulation activities are directed towards achieving individuals' conscious or unconscious goals. They are aimed to remediate or moderate the overly intense negative emotional or positive emotional state. The emotion regulation adaptation skill has also been recognised as a major component of the Emotional Intelligence concept (Gross \& Barrett, 2011).

Lazarus (1991) postulates two stages of individual's emotion Gross \& Barrett mechanism. The first stage is the primary appraisal stage, which evaluates the relevance of the potential emotion elicitor to the individual. In a similar vein, Lazarus (1991) proposes that the primary appraisal of the emotion regulation process should take place before an emotion has become fully activated. The evaluation then leads to a coordinated set of behavioural, psychological or experiential emotional responses (Lazarus, 1991). According to (Gross \& Barrett, 2011), the coordinated responses of adaptive strategies should focus on using available resources as a means to manage problematic situations and thus improve the elicited emotional state. For instance, a weak student who is unprepared for a test might decide to stay up late 
as a strategy to make him feel better. Similarly, doing breathing exercises before a sprint event by athletics is another example of an emotion regulation strategy.

The second emotion regulation process occurs after the emotion has been fully generated (Gross \& Barrett, 2011; Lazarus, 1991). Lazarus (1991) refers to this regulation process as the secondary appraisal phase. The aim of the secondary regulation process is to manage the elicited emotional state. It consists of behaviour or cognitive responses or strategies that are designed to reduce, overcome, or tolerate the demands placed on the individual. People are observed using different strategies to deal with elicited emotional state depending on their background, knowledge and culture (Bandura, 2010).

For example, Asian students are culturally more reserved. To them, revealing personal problems to others can cause shame for themselves. Thus, they tend to keep to themselves or endure the problem to themselves. Reference (Yeh, 2005) found that the Asian immigrant students in the US are more likely to use religious practice as compared to their local students. In contrast, European students are more self-expressive in confronting with learning problems (Wigfield \& Jacquelynne, 2002). They are more likely to discuss their problems with classmates and teachers.

Lazarus (1991) has classified the strategies used by individuals to deal with different intensities of the elicited emotional state into two categories. The first category is the emotion-focused strategies. Emotion-focused (EF) strategies refer to thoughts or actions whose goal is to relieve the emotional impact of stress. They are mainly palliative in the sense that such strategies do not actually alter the threatening domain or damaging environment but are apt to just make the person feel better (Lazarus, 1991). Avoiding thinking about trouble, denying that anything is wrong, distancing or detaching oneself by breathing or doing relaxation therapy are examples of emotion-focused strategies.

There is empirical evidence to suggest that the deployment of emotion-focused strategies such as relaxation therapy and supplication are effective in improving people emotional state and their personality traits (Bandura, 2011; Pekrun, 2011). For example, Fredrickson (1998) attributed the ability of patients to control their hostile and aggressive behaviour to the relaxation exercises sessions that the patients undertook. There is also evidence that relaxa- 
tion exercises are clinically effective in treating headaches. For instance, Graziano et al. (2007) found that relaxation exercises help to reduce between $40 \%$ and $80 \%$ of tension headaches that patients suffered.

Several studies suggest that there is a positive relationship between relaxation exercises and students' performance within the classroom environment. For instance, Benson and his team study the relationship between the "relaxation response" curriculum and academic achievement amongst middle class students (Benson et al., 2000). The results suggest that students who had more exposure to the relaxation exercises curriculum showed an improvement in their grade point average scores, work habit scores and cooperation scores over the course of a two-year period. Recently, there has been an attempt to develop commercial computer-based relaxation exercises software which has produced a positive result (TestEdge ${ }^{\circledR}$ 2003). Results of the study revealed that the students who used the software were observed to record a $35 \%$ improvement in math scores and a 14\% improvement in reading scores.

It is also noteworthy to review the effect of supplication in general towards student's academic achievement. According to Seligman (1991), positive affirmation is the central to the supplication strategy. People who practice supplication strategy will have a greater sense of self-control or self-awareness over their ability and resources. As a result, they are expected to be better in managing their affective state (Gross \& Barrett, 2011; Love, 2005).

Furthermore, Canfield (2003) and Henshaw (2005) have pointed out a further benefit of supplication. They believe that supplication is a powerful tool for building a sense of worthiness and self-concept. In an educational context, the improvement of self-concept has often been associated with better academic achievement. Empirical studies have been also been conducted on the relationship between supplication and relaxation exercises, and academic achievement. For example, Britton \& Virean (1999) found in their study that relaxation and supplication significantly decrease test anxiety amongst the repeat students of the Texas Academic Skills Program Mathematics Laboratory. In another study (Henshaw, 2005), conducted in the US (North Miami Beach, Florida), supplication and relaxation exercises were used as additional techniques to treat addiction. Results showed that those who subscribed to this method reported greater improvement in their self-concept, stayed longer in recovery and generally had a better quality of life. 
Problem-focused (PF) strategies are the second category employed by people in regulating their emotional states. (Lazarus, 1991) refers problem-focused strategies as active or as direct cognitive or adaptive behavioural efforts to improve the troubled person-environment relationship. It involves attempting to change the problem by generating and implementing options and steps to solve or make the problem less stressful (Baker \& Barenbaum, 2008). Seeking information about what to do or confronting the person or persons responsible for one's difficulty are examples of such strategies. For example, (Lester et al., 1999) reported that the deployment of different problem-focused coping strategies (i.e. by scaffolding students using different level of help) have positive impact in their affective state and improved their performance. Likewise, Bandura (2010) reported that the use of PF strategies (different levels of help) improved students' problem-solving skills.

Within the self-regulated tutoring system (SRT) context, three approaches of PF strategies deployment are noted; (i) to provide feedback or analysis of the students' answers, (ii) to provide different level of help (i.e. scaffolding) to the students and (iii) to organize or suggest student's next task. Furthermore, there is evidence of the successful use of these strategies which not only improve students' affective states, but also their academic achievement (Conati \& Zhou, 2002; Gaines, 2005). In addition, Lazarus and his colleagues' longitudinal studies (e.g. Folkman \& Lazarus, 1988; Lazarus, 1991) provide empirical support for the premise that people use both the emotion-focused strategy and problem-focused strategy for coping with problematic environment.

However, to our knowledge, very few attempts have been made to study about students' emotion regulation strategies within tutoring system context, particularly on students' regulation strategies during stressful learning situation. It is therefore, warrants a need to study the suitable regulation strategies during a tutoring session. The identified strategies can then be deployed as the emotion regulation strategies in a self-regulated tutoring system environment.

\section{Method}

\section{Participants}

We conducted an exploratory study among UNITEN students to examine their selfregulation strategies during learning episodes. In this study, 227 unpaid students (132 males 
and 95 females) from the College of Computer Science and Information Technology, Universiti Tenaga Nasional, Malaysia took part.

\section{Instrumentation}

This questionnaire consists of 25 different possible strategies containing a wide range of thoughts and acts that student use to deal with the internal and/or external demands of specific stressful encounters. Each strategy is presented in a scale of 0 to 3 . A value of 0 means the strategy is not used by the student, while a value of 3 represents a frequently used strategy. The survey was distributed in person to the students at the beginning of their lesson. No time limit was imposed in this study. Students were asked to hand in the survey as soon as they had completed the questionnaire.

\section{Procedure}

We use an adapted version of Ways of Coping questionnaire (WCQ) (Folkman \& Lazarus, 1988). The Ways of Coping questionnaire has demonstrated good reliability and validity (Folkman \& Lazarus, 1988). In recent years, many researchers (e.g Lundqvista \& Ahlstrfmb, 2006; Yip \& Rowlinson, 2006) have reported reliable findings in the use of the WCQ questionnaire in assessing individual coping strategies in various disciplines (i.e. medicine, sport science and education).

\section{Statistical Analysis}

The score of mean was used to compare the frequency of the 25 different selfregulation strategies used by the students. In addition, correlation analysis was also test among the top 10 self-regulation strategies was conducted so that more insight of the selected self-regulation strategies by the students can be unfolded.

\section{Results}

Using Lazarus's classification, students' self-regulation strategies dealing with stressful learning episodes were examined and classified into emotion-focused or problem-focused strategies. As a result, 13 strategies were classified as the emotion-focused strategy and an- 
other 12 were classified as problem-focused strategy. The complete classification is presented in Table 1.

Table 1. Students' Self-Regulation Strategies Dealing With Stressful Learning Episodes

\begin{tabular}{clccc}
\hline No & \multicolumn{1}{c}{ Self-Regulation Strategy } & Group & Mean & Std. \\
& & & Dev \\
\hline 1 & I pray/ supplication & EF & 2.53 & 0.84 \\
2 & Try to analyze the problem in order to understand it better. & PF & 2.32 & 0.73 \\
3 & Try to look on the bright side of things. & EF & 2.21 & 0.73 \\
4 & I am inspired to do something creative. & EF & 2.07 & 0.83 \\
5 & Change something so things will turn out all right. & PF & 2.06 & 0.73 \\
6 & Talk to someone who can do something concrete about the problem. & PF & 2.06 & 0.86 \\
7 & I make a plan of action and follow it. & PF & 2.05 & 0.78 \\
8 & Stand my ground and fight for what I want. & PF & 2.02 & 0.82 \\
9 & Wish that I can change what is happening or how I feel. & EF & 2.01 & 0.85 \\
10 & Ask a relative or friend I respect for advice. & PF & 1.95 & 0.91 \\
11 & Talk to someone about how I'm feeling. & $\mathrm{EF}$ & 1.91 & 0.94 \\
12 & Wish that the situation would go away or somehow be over with. & $\mathrm{EF}$ & 1.91 & 0.84 \\
13 & I try to keep my feelings from interfering with other things too much. & $\mathrm{EF}$ & 1.87 & 0.85 \\
14 & I jog or exercise. & $\mathrm{EF}$ & 1.84 & 0.72 \\
15 & Hope a miracle will happen. & $\mathrm{EF}$ & 1.81 & 1.05 \\
16 & Have fantasies or wishes about how things might turn out. & $\mathrm{EF}$ & 1.73 & 1.03 \\
17 & I feel that time will make a difference. & $\mathrm{EF}$ & 1.73 & 1.00 \\
18 & I daydream or imagine a better time or place than the one I am in. & $\mathrm{EF}$ & 1.72 & 0.91 \\
19 & Go away from it for awhile; try to rest or take a vacation. & $\mathrm{EF}$ & 1.64 & 1.08 \\
20 & I try not to act too hastily or follow my first hunch. & $\mathrm{PF}$ & 1.64 & 1.02 \\
21 & Go on as if nothing is happening. & $\mathrm{PF}$ & 1.48 & 0.99 \\
22 & I wait to see what will happened before doing anything. & $\mathrm{PF}$ & 1.43 & 0.94 \\
23 & Accept it since nothing can be done. & $\mathrm{EF}$ & 1.42 & 0.99 \\
24 & Go along with fate; sometimes I just have bad luck. & $\mathrm{EF}$ & 1.26 & 0.94 \\
25 & Try to forget the whole thing. & $\mathrm{EF}$ & 1.18 & 1.08 \\
\hline
\end{tabular}

Result from the survey clearly indicates that students used both the emotion-focused and problem-focused strategies. For instance, the most frequently used strategy by students was an emotion-focused strategy (i.e. Supplication (praying or doa) with a mean of 2.53 (SD $=0.83$ ) and followed by a problem-focused strategy (i.e. trying to analyse the problem in order to understand it better with a mean of $2.31, \mathrm{SD}=0.72$ ). Also, the students have selected a combination of four emotion-focused strategies and six problem- focused strategies as the top ten self-regulation strategies in dealing with stressful learning episodes (see Table 1).

This has provided some evidence that students used a combination of emotion-focused and problem-focused strategies while dealing with potential affect eliciting events. To get 
more insight into this study, a correlation test among the top 10 self-regulation strategies was conducted.

Table 2 below shows the correlation analysis within the top ten self-regulation strategies selected by students. A very strong positive correlation can be observed between the most frequently used emotion-focused regulation strategy "(I pray/supplication - regulation strategy 1)" and the two problem-focused strategies "(i.e. regulation strategies 2 and 6)". This means that those who used the "I pray/supplication" strategy were most likely to also use the "Try to analyze the problem in order to understand it better" and "Talk to someone who can do something concrete about the problem" strategies as a means to deal with learning episodes.

Similarly, student who deployed the second strategy (i.e. "Trying to analyse the problem in order to understand it better") was likely to also use the emotion-focused strategies (i.e. regulation strategies 1 and 4) and problem-focused strategies (regulation strategies 5 and 7). In fact, consistent correlation trending was also observed for the regulation strategies deployed by the students (see Table 2).

Table 2. Correlations within the Self-Regulation Strategies Group

\begin{tabular}{|c|c|c|c|c|c|c|c|c|c|c|}
\hline \multicolumn{11}{|c|}{ Self-regulation Strategies } \\
\hline & $1(\mathrm{EP})$ & $2(\mathrm{PF})$ & $3(\mathrm{EF})$ & $4(\mathrm{EP})$ & $5(\mathrm{PF})$ & $6(\mathrm{PF})$ & $7(\mathrm{PF})$ & $8(\mathrm{PF})$ & 9 (EP) & $10(\mathrm{PF})$ \\
\hline $1(\mathrm{EF})$ & 1.0 & $.169(*)$ & $.225(* *)$ & $.213(* *)$ & 0.11 & $.167(*)$ & 0.12 & $.159(*)$ & 0.09 & $.366(* *)$ \\
\hline $2(\mathrm{PF})$ & $.169(*)$ & 1.00 & $.191(*)$ & $.289(* *)$ & $.256(* *)$ & 0.15 & $.390(* *)$ & 0.09 & 0.03 & 0.11 \\
\hline $3(\mathrm{EF})$ & $.225(* *)$ & $.191(*)$ & 1.00 & $.319(* *)$ & $.213(* *)$ & $.183(*)$ & $.245(* *)$ & $.320(* *)$ & -0.07 & $.188(*)$ \\
\hline $4(\mathrm{EF})$ & $.213(* *)$ & $.289(* *)$ & $.319(* *)$ & 1.00 & $.193(*)$ & 0.12 & $.183(*)$ & $.261(* *)$ & 0.07 & 0.13 \\
\hline $5(\mathrm{PF})$ & 0.11 & $.256(* *)$ & $.213(* *)$ & $.193(*)$ & 1.00 & 0.09 & $.198(* *)$ & $.239(* *)$ & 0.11 & 0.10 \\
\hline $6(\mathrm{PF})$ & $.167(*)$ & 0.15 & $.183(*)$ & 0.12 & 0.09 & 1.00 & 0.03 & 0.15 & 0.10 & $.417(* *)$ \\
\hline 7 (PF) & 0.12 & $.390(* *)$ & $.245(* *)$ & $.183(*)$ & $.198(* *)$ & 0.03 & 1.00 & $.26(* *)$ & -0.12 & 0.02 \\
\hline 8 (PF) & $.159(*)$ & 0.09 & $.320(* *)$ & $.261(* *)$ & $.239(* *)$ & 0.15 & $.262(* *)$ & 1.00 & 0.00 & 0.09 \\
\hline $9(\mathrm{EF})$ & 0.09 & 0.03 & -0.07 & 0.07 & 0.11 & 0.10 & -0.12 & 0.00 & 1.00 & 0.14 \\
\hline $10(\mathrm{PF})$ & $.366(* *)$ & 0.10 & $.188(*)$ & 0.12 & 0.1 & $.417(* *)$ & 0.02 & 0.08 & 0.13 & 1 \\
\hline
\end{tabular}

** Correlation is significant at the 0.01 level (2-tailed)

* Correlation is significant at the 0.05 level (2-tailed) 
Thus, it has provided yet evidence that students used a combination of emotionfocused and problem-focused to regulate their affective state dealing with potential affect eliciting events. However, there is some concern about the influence of gender towards students' behaviour. Across literature, some studies have shown that gender different could influence students' behaviour in dealing with learning episodes. Thus, to get more insight into the regulation strategies among students, comparison of students based on different genders was carried out.

Table 3 depicts the five frequently used self-regulation strategies by the male and female students. It was observed that first two most frequently strategies used by both groups were similar. The female students were noted to deploy the ("I pray/supplication") strategy more often than the male students and the different is statistically significant (see T-test result in Table 3). However, different approaches were noted for the other three strategies. For the female students, they were more likely to share their problem or seek for help from others (i.e. "Talk to someone who can do something concrete about the problem and Talk to someone about how I'm feeling").

In contrast, the male students adopted for more reserved and challenging approaches. They did not want to share their problem with other. Instead, they were looking for direct solution for the problem (i.e. "I make a plan of action and follow it" and "I am inspired to do something creative").

Table 3. Frequently Used Self-Regulation Strategies Deployed By Students

\begin{tabular}{cccccc}
\hline \multicolumn{2}{c}{ Female students } & \multicolumn{5}{c}{ Male students } \\
\hline Self Regulation Strategies & Mean & SD & Self- Regulation Strategies & Mean & SD \\
1 & 2.73 & 0.68 & 1 & 2.42 & 0.90 \\
2 & 2.33 & 0.74 & 2 & 2.31 & 0.73 \\
6 & 2.21 & 0.70 & 3 & 2.22 & 0.73 \\
3 & 2.19 & 0.74 & 4 & 2.11 & 0.83 \\
11 & 2.11 & 0.86 & 7 & 2.07 & 0.79 \\
\hline
\end{tabular}

Nevertheless, in line with the overall finding, both groups were also observed to use the combination of emotion-focused and problem-focused strategies in dealing with potential 
stressful learning episodes. In addition, except for "I pray/supplication" strategy, no significant differences were noted for the different self-regulation strategies deployed by the male and female students (see Table 4).

Table 4. Significant Test between Self-Regulation Strategies Used By Male and Female Students

\begin{tabular}{|c|c|c|c|}
\hline Self Regulation Strategy & Gender & Mean & Sig \\
\hline \multirow[t]{2}{*}{ 1. I pray/ supplication } & Male & 2.42 & $\mathrm{U}(227)=5004, \mathrm{Z}=-3.29, \mathrm{p}$ \\
\hline & Female & 2.73 & $<0.05$ \\
\hline \multirow{2}{*}{$\begin{array}{l}\text { 2. Try to analyze the problem in } \\
\text { order to understand it better. }\end{array}$} & Male & 2.30 & $\mathrm{U}(227)=6140, \mathrm{Z}=-0.74, \mathrm{p}$ \\
\hline & Female & 2.33 & $>0.05$ \\
\hline \multirow[t]{2}{*}{ 3. Try to look on the bright side of things. } & Male & 2.21 & $\mathrm{U}(227)=6041, \mathrm{Z}=-0.52, \mathrm{p}$ \\
\hline & Female & 2.19 & $>0.05$ \\
\hline \multirow{2}{*}{ 4. I am inspired to do something creative. } & Male & 2.10 & $\mathrm{U}(227)=6136, \mathrm{Z}=-0.29, \mathrm{p}$ \\
\hline & Female & 2.00 & $>0.05$ \\
\hline \multirow{2}{*}{ 5. Change something so things will turn out all right. } & Male & 2.04 & $U(227)=6001, Z=-0.60, p$ \\
\hline & Female & 2.09 & $>0.05$ \\
\hline \multirow{2}{*}{$\begin{array}{l}\text { 6. Talk to someone who can do something concrete about } \\
\text { the problem. }\end{array}$} & Male & 1.97 & $\mathrm{U}(227)=6001, \mathrm{Z}=-0.60, \mathrm{p}$ \\
\hline & Female & 2.20 & $>0.05$ \\
\hline \multirow{2}{*}{ 7. I make a plan of action and follow it. } & Male & 2.07 & $\mathrm{U}(227)=5745, \mathrm{Z}=-1.15, \mathrm{p}$ \\
\hline & Female & 2.01 & $>0.05$ \\
\hline \multirow{2}{*}{ 8. Stand my ground and fight for what I want. } & Male & 2.06 & $\mathrm{U}(227)=5554, \mathrm{Z}=-1.62, \mathrm{p}$ \\
\hline & Female & 1.95 & $>0.05$ \\
\hline \multirow{2}{*}{ 9. Wish that I can change what is happening or how I feel. } & Male & 1.98 & $\mathrm{U}(227)=5592, \mathrm{Z}=-1.49, \mathrm{p}$ \\
\hline & Female & 2.06 & $>0.05$ \\
\hline \multirow{2}{*}{ 10. Ask a relative or friend I respect for advice. } & Male & 1.91 & $\mathrm{U}(227)=5984, \mathrm{Z}=-0.63, \mathrm{p}$ \\
\hline & Female & 2.01 & $>0.05$ \\
\hline
\end{tabular}

We further conduct an insight study to determine the potential emotion-regulation strategies based to be integrated into a self-regulated tutoring system framework. Using Lazarus classification, the top ten (10) emotion focused strategies is then classified into two categories; namely the active and passive regulation strategies ( Table 5).

Table 5. The classification of Emotions-Focused strategies

\begin{tabular}{lcccc}
\hline Self- Regulation Strategy & Group & mode & Mean & SD \\
\hline I pray/ supplication & EF & A & 2.53 & 0.84 \\
Try to look on the bright side of things. & EF & P & 2.21 & 0.73 \\
Wish that I can change what is happening or how I feel. & EF & P & 2.01 & 0.85 \\
Talk to someone about how I'm feeling. & EF & P & 1.91 & 0.94 \\
Wish that the situation would go away or somehow be & EF & P & 1.91 & 0.84 \\
over with. & & & & \\
I try to keep my feelings from interfering with other things & EF & A & 1.87 & 0.85 \\
too much. & & & & \\
I jog or relaxation exercise. & EF & A & 1.84 & 0.72 \\
Hope a miracle will happen. & EF & P & 1.81 & 1.05 \\
Have fantasies or wishes about how things might turn out. & EF & P & 1.73 & 1.03 \\
I feel that time will make a difference. & EF & P & 1.73 & 1.00 \\
\hline
\end{tabular}


Following the classification (Table 6), three (3) active emotion-regulation strategies as compared to seven (7) for the passive strategies were identified. However, the passive strategies such as "Wish that the situation would go away or somehow be over with", "Hope a miracle will happen" and "Have fantasies or wishes about how things might turn out" are less relevant to be deployed in a tutoring system environment. This is because of the nature of these strategies, that is, they are passive actions (merely hoping and wishing) which do not help much to improve students' sense of learning awareness and self-control over their learning events. Thus, these strategies are difficult to be implemented in a self-regulated tutoring system.

Besides, the reaction phase of a self-regulated tutoring system is active in nature. According to Lazarus (2001), the active strategies are active efforts that help people reinterpret, regulate and produce effective strategies to improve their affective state. They are not aimed at providing a solution or modifying the domain or environment, rather, they are active selforiented strategies aimed at maintaining the individual's psychological affective state). Thus, we assert that active emotion-focused strategies are more suitable to be integrated in a selfregulated tutoring system.

The first potential candidate of the emotion-focused strategy is "I pray/ supplication" strategy. It is the most commonly used by the respondents (both male and female students) of the study. Thus, it should naturally be a good candidate for the emotion-focused strategies. The second candidate is "I try to keep my feelings from interfering with other things too much" strategy. Though, it is an active strategy, the strategy is very difficult to be implemented in the self-regulated affective framework. Perhaps, the strategy is more relevant to a collaborative learning environment, which is, beyond the scope of SRT framework. Therefore, we assert that the "I try to keep my feelings from interfering with other things too much" strategy is not a good candidate for the SRT framework.

"I jog and relaxation exercise" strategy is the other potential candidate for selfregulated tutoring system framework. The strategy is about an individual's attempt to minimize and regulate emotional impact by diverting their focus from the emotion-eliciting situation or events (Folkman \& Lazarus, 1988). However, in the learning context of SRT framework, jogging is not suitable strategy to deploy as it requires extensive physical movement which could distract student's learning engagement and activities. In contrast, relaxation exercises require less physical movement and are more suitable for students. 
However, as suggested by some literature (Yeh, 2005), the implementation of these strategies is influenced by the student's religion and culture (i.e. especially in Malaysian context). Thus, it is important to conduct comparison study of these strategies based on student's religion and cultural background. Therefore, further analysis was carried out to examine the students' emotion-focused strategies between two experimental groups; namely the Muslim and non-muslim. Results of the analysis are presented as in the Table 6.

Table 6. The analysis of self-regulation strategies between muslim and non-muslim

\begin{tabular}{lllrrl}
\hline No & $\begin{array}{l}\text { Self-Regulation } \\
\text { strategy }\end{array}$ & group & Mean & $\begin{array}{l}\text { Std. } \\
\text { Dev }\end{array}$ & Sig \\
\hline 1 & I pray/supplication & Muslim & 2.63 & 0.70 & $\mathrm{U}(227)=4208, \mathrm{Z}=-1.88, \mathrm{p}$ \\
& & Non-muslim & 2.33 & 1.04 & $<0.05$ \\
2 & I jog or relaxation exer- & Muslim & 1.80 & 0.75 & $\mathrm{U}(227)=4309, \mathrm{Z}=-1.36, \mathrm{p}$ \\
& cise. & Non-muslim & 1.91 & 0.66 & $\mathrm{p}>0.05$ \\
\hline
\end{tabular}

No significant differences was noted for the "I jog or relaxation exercise" strategies for both groups. As a consequence, at least to these groups of students, common mechanism of the strategies could be developed, deployed and integrated into the self-regulated tutoring system framework. In contrast, significant difference was observed for "I pray/supplication" strategy between the Muslim and non-Muslim students. Students of both groups were observed to use different regulation strategy. As such, we assert that the development and deployment of supplication intervention strategy within self-regulated tutoring system framework should be adapted to different student's religion.

\section{Discussion and conclusion}

The results of this experiment in general has provided some evidence to support the use of both emotion-focused and problem-focused strategies deployed by students in dealing with potential stressful learning episodes. Moreover, the significant correlation between the emotion-focused strategies and the problem-focused strategies provides yet more evidence. It is also in accordance with the affect regulation model (Lazarus, 1991), which suggests that both emotion-focused strategies and the problem-focused strategies are used by individual to deal with stressful learning episodes. Moreover, two potential candidates for active regulation 
strategies to be integrated into the SRT framework have been identified. The first potential strategy is the supplication strategies, and the second potential strategy is the relaxation exercise strategy.

Many studies from across a wide research spectrum have also established a positive correlation among the relaxation exercise and supplication statregies with students' learning state improvements (e.g. Pekrun, 2011). Through physical activities such as deep breathing exercises and progressive muscle relaxation, an individual can reduce his physiological affective state level. Likewise, the supplication strategies can increase students' awareness which enable them to relax when they become stressed during a tutoring session. Besides, both the relaxation exercise and supplication strategies can improve blood circulation by opening some blood vessel around ad the stressed body and therefore relieve the stress. Thus, relaxation exercises and supplication are suitable to be a part of the emotion-focused strategies of a tutoring system framework.

\section{Limitation of the study}

The first limitation of the study concerns the temporal frequency of the study. Standard questionnaire design principles require data on behaviour (especially to collect data on individual's regular behaviour) to be collected over a period of time (e.g. every day or once a week). By contrast, this study was conducted as a one-off event. However, in this study, students were required to report their past experiences (not present) dealing with stressful encounter. Note that others have also used a one-off approach in measuring individuals' past experience (Yip \& Rowlinson, 2006).

The second concern is about the use of a narrow scale range (0-3) in the WCQ questionnaire. Such a severe range tends to inflate the size of bivariate correlation and hence indicates that a higher threshold value than 0.60 should be used for the reliability coefficient. However, the scale range is a part of the standard WCQ questionnaire which is regarded as one of the most widely used coping strategies apparatus (Goetz et al. 2008). As such, the use of similar scale range is important so that the results of our study can be compared with other studies. Moreover, in an exploratory study, a threshold value of 0.60 as the reliability coefficient is accepted (Field, 2009). 


\section{Implications and Future Research}

In sum, the implication of the study can be summarised into two folds: Firstly, the results suggest that a self-regulated tutoring system, at least, in part should integrate emotionfocused and problem-focused strategies as the means to regulate students' affective state. Secondly, the results have also provided some potential candidates of emotion-focused and problem-focused strategies that can be used to regulate student's elicited emotional state in the self-regulated tutoring system framework.

Theferore, it is very important to consider the inclusion of the emotion-focused strategies into a tutoring system framework. Such inclusion will not only optimize the ability of students' in learning, but eventually bring the computer- human interations decipline closer to human nature.

\section{References}

Baker, J. P., \& Berenbaum, H. (2008). The efficacy of problem-focused and emotional approach interventions varies as a function of emotional processing style. Cognitive Therapy and Research, 32(1), 66-82

Bandura, A. (2010). Self-efficacy. In The Corsini Encyclopedia of Psychology (4th Ed. pp. 1534-1536). Hoboken, New Jersey: John Wiley \& Sons.

Bandura, A. (2011). Social cognitive theory. In P. A. M. van Lange, A. W. Kruglanski, \& E. T. Higgins (Eds.). Handbook of social psychological theories. (pp. 349-373). London: Sage

Barret, L. F., Salovey, P., Mayer, J. D. (2002). The Wisdomin Feeling: Psychological Processes in Emotional Intelligence: Guilford Press.

Benson, H. M., Wilcher, B. G., Huggins, E., Zuttermeister, M. E., Myers, P. C., \& Friedman, R. (2000). Academic performance among middle school students after exposure to a relaxation response curriculum. Journal of Research and Development in Education, $33,33(3)$.

Boekaerts, M. (1993). Being concerned with well-being and with learning. Educational Psychologist , 28 (2), 149-167. 
Boud, D., \& Miller, N. (1996). Synthesising traditions in learning from experience. Working with Experience. (D. Boud, \& N. Miller, Eds.) Animating Learning, 14-24.

Bourne, E. (2000). The Anxiety and Phobia Workbook. (Vol. 3). Oakland, CA: New Harbinger Publications, Inc.

Britton, B., \& Virean, D. (1999). Effects of relaxation and positive self-talk inteventions on test anxiety of mathematics TASP test repeaters. (Texas academic skills program). Dissertation Abstracts International Section A: Humanities \& Social Sciences, 59, 10A

Conati, C., \& Zhou, X. (2002). Modelling students' emotions from cognitive appraisal in educational games. In International Conference on Intelligence Tutoring System. Biarritz,

Cornelius, R. R. (1996). The science of emotions: Research and tradition in the psychology of emotion. London: Prentice Hall.

David, D., Schnur, J., Birk, J. (2004). Functional and Dysfunctional feelings in Ellis' cognitive theory of emotion: An empirical analysis. Cognition \& Emotion, 18(6), 2004.

Deckro, G., Wilcher, M., B.K., H. M., J., D., Myers, P., B., G., et al. (2002). The Evaluation of a Mind/Body Intervention to Reduce Psychological Distress and Perceived Stress in College Students. Journal of American College Health , 50 (6), 281-287.

Deffenbacher, J. L. (2000). Social skills training. . In A. E. Kazdin, Encyclopaedia of psychology (Vol. 7, pp. 370-373). Washington, D.C.: American Psychological Association/Oxford University Press.

D'Mello, S., Picard, R., \& Graesser, A. (2007). Towards An Affect-Sensitive AutoTutor. IEEE Intelligent Systems, Special issue on Intelligent Educational Systems, 22 (4), 53 61.

Efklides, A., \& Volet, S. (2005). Feelings and emotions in the learning process. Learning and Instruction [Special issue], 15 (5), 1-10.

Eysenck, M. (1998). Psychology, an Integrated Approach Harlow: Longman.

Field, A. (2009). Discovering Statistics Using SPSS (3nd Edition), SAGE publication.

Folkman, S., \& Lazarus, R. S. (1988). Manual for the Ways of Coping Questionnaire. Palo Alto, CA: Consulting Psychologist Press. 
Fredrickson, B. L., \& Levenson, R. W. (1998). "Positive emotions speed recovery from the cardiovascular sequelae of negative emotions." Cognitive and Emotion, 12: 191-220.

Fredrickson, B. L., \& Losada, M. F. (2005). "Positive Affect and the Complex Dynamics of Human Flourishing." American Psychologist 60: 678-686.

Fridja, H. C. (1986). The Emotions, Cambridge U. Press.

Gaudreau, P., Blondin, J.P. (2002). "Development of a questionnaire for the assessment of coping strategies employed by athletes in competitive sport setting." Psychology of Sport and Exercise 3(1): 1-34.

Gaines, A. M. (2005). Houston Independent School District Executive Summary. Retrieved $\begin{array}{llll}\text { Spetember } & 10, & 2011 & \text { from }\end{array}$ http://www.houstonisd.org/vgn/images/portal/cit_23015118/1360204459/Executive Summary_Gross Elementary Relaxation1.pdf

Goetz, T., Frenzel, A. C., Hall, N. C., \& Pekrun, R. (2008). Antecedents of academic emotions: Testing the internal/external frame of reference model for academic enjoyment. Contemporary Educational Psychology, 33(1), 9-33

Gross, J. J. and L. F. Barrett (2011). "Emotion generation and emotion regulation: One or two depends on your point of view." Emotion Review: 3, 8-16. doi:10.1177/1754073910380974.

Graziano, P., Reavis, R., Keane, S. \& Calkins, S. (2007). The role of emotion regulation and the student-teacher relationship in children's academic success. Journal of School Psychology,45, 3-19.

Gross, J. J., Sheppes, G. \& Urry, H. L. (2011). Emotion generation and emotion regulation: A distinction we should make (carefully). Cognition \& Emotion, 25, 765-781.

Hanin, Y. L. (2000). Emotions in Sport, Human Kinetics.

Henshaw, H. (Producer) (2005). Individualized positive affirmations for improving selfesteem. Retrieved from http//www.articlecity.com/articles/selfimprovement_and_motivation/article_3557.shtml

Isen, A. M., \& Reeve, J. (2005). "The influence of positive affect on intrinsic and extrinisic motivation: Facilitating enjoyment of play, responsible work behavior, and selfcontrol." Motivation and Emotion 29(4): 297-325. 
Järvenoja, H., \& Järvelä, S. (2009). Emotion control in collaborative learning situations: Do students regulate emotions evoked by social challenges? British Journal of Educational Psychology , 79, 463-481.

Johnson, W. L., \& Rickel, J. (1998). Steve: An animated pedagogical agent for procedural training in virtual environments. SIGARD Bulletin , 8, 16-21.

Kay, R. H., Loverock, H. (2008). Assessing emotionsrelated to learningnew software: The computer emotion scale. Computers in Human Behavior, 24, 1605-1623.

Lam, A. G., Zane, S., \& Nolan, W. (2004). Ethnic Differences in Coping with Interpersonal Stressors : A Test of Self-Construals as Cultural Mediators. Journal of Cross-Cultural Psychology , 35 (4), 446-459.

Lazarus, R. S. (1999). Stress and emotion: A new synthesis New York, Springer.

Lazarus, S. R. (1991). Emotion and Adaptation, Oxford U. Press.

Lester, J. C., Voerman, J. L., Towns, S. G., \& Callaway, C. B. (1999). Deictic believability: Coordinating gesture locomotion and speech on lifelike pedagogical agents. Applied Artificial Intelligence, 13, 383-414.

Linnenbrink, E. A. (2006). Emotion research in education: Theoretical and methodological perspectives on the integration of affect, motivation, and cognition. Educational Psychology Review , 18, 307-314.

Lundqvista, L., \& Ahlstrfmb, G. (2006). Psychometric evaluation of the Ways of Coping Questionnaire as applied to clinical and nonclinical groups. Journal of Psychosomatic Research , 60, 485- 493.

Margolis, H., McCabe., Patrick. (2006). Improving Self-Efficacy and Motivation: What to Do, What to Say. Interventionin School and Clinic. 41(4), 218-227.

Mayer, J. D., \& Salovey, P. (1993). The intelligence of emotional intelligence. Intelligence, $17(4), 433-442$.

Nietfield, J., Cao, L., \& Osborne, J. (2005). Metacognitive monitoringaccuracy and student performance in the postsecondary classroom. The Journal of Experimental Education, 74(Gaudreau), 7-28.

Ortony, A., Clore, G., \& Collins, A. (1988). The cognitive structure of emotion. Cambridge U. Press. 
Pajares. (2002). Self-efficacy beliefs in academic contexts: An outline. Retrieved September 10, 2011, from http://des.emory.edu/mfp/efftalk.html

Pekrun, R. (2011). Emotions as Drivers of Learning and Cognitive Development in New Perspectives on Affect and Learning. New Perspectives on Affect and Learning Technologies.

Pekrun, R., \& Linnenbrink-Garcia, L. (2012)Academic emotions and students engagement. Handbook of research on student engagement, 259-282.

Picard, R. W. (2010). Affective Computing: From Laughter to IEEE. IEEE Transactions, Volume: 1 (Issue:1), 11 - 17, ISSN: 1949-3045.

Picard, R. W. (2007). Toward Machines with Emotional Intelligence. In G. Matthews, M. Zeidner, \& R. D. Roberts, The Science of Emotional Intelligence: Knowns and Unknowns. Oxford, UK: Oxford University Press.

Qu, L., \& Johnson, L. (2005). Detecting the learner's motivational states in an interactive learning environment. In C. K. Looi (Razek), Proceeding Artificial Intelligence in Education (pp. 547-554). Amsterdam: IOS Press.

Renniger, K. A. (1992). Individual Interest and Development: Implication for theory and practice. In K. A. Renniger, \& Krapp, A. (Razek), The Role of Interest in Learning and Development (pp. 361-395). Hillsdale: Erlbaum.

Reilly, R., Kort, B., \& Picard, R. (2001). External Representation of Learning Process and Domain Knowledge: Affective State as a Determinate of its Structure and Function. Proceedings the IEEE Artificial Intelligence in Education Conference. San Antonio, Texas.

Schutz, P. A., Pekrun, Reinhard. (2007). Emotion in Education, Academic Press.

Seligman, M. E. P. (2002). Learning Optimism. New York: A. A. Knopf.

TestEdge®.(2003). $\quad$ Retrieved September, 20,2012 from http://www.heartmath.org/education/testedge/why.php.

Tiba, A., Szentagotai, A. (2005). Positive Emotions and Irrational Beliefs: Dysfunctional positive emotions in healthy individual. Journal of Cognitive and Bheavior Psychotherapies. 53-72. 
Tugade, M. M. F., Frederickson, B. L. (2004). "Resilient individuals use positive emotions to bounce back from negative emotional experiences." Journal of Personality and Social Psychology 86(320-333.).

Watson, D., Clark, L., \& Tellegen, A. (1988). Development and validation of brief measures of positive and negative affect: the PANAS scales. Journal of Personality and Social Psychology , 54, $1063-1070$.

Wigfield, A. L., \& Jacquelynne, S. E. (2002). Motivational beliefs, values, and goals. Annual Review of Psychology, 53, 109-132.

Van der Meij, H. (2008 ). " Designing for user cognition and affect in software instructions " Learning and instruction 18(18-29).

Yeh, T. L. (2005). "Issues of collage persistence between asian and asian pacific american students." Journal of College Student Retention: Research, Theory and Practice 6(1): 81-96.

Yip, B., \& Rowlinson, S. (2006). Coping Strategies among Construction Professionals:Cognitive and Behavioural Effort to Manage Job Stressors. Journal for Education in the Built Environment , 1 (2), 70-79. 